【研究简报】

\title{
青藏高原西部吉隆-鲁谷地区的重力场 与地壳构造
}

王谦身 武传真江为为
(中国科学院地球物理研究所, 北京 100101)

\section{关链词青藏高原西部 吉隆-兽谷地区 熏力 地壳构造}

根据青藏高原西部吉隆-鲁谷地区地面重力探测的最新资料, 研究了该地区的重力场特 征、测点高程与布格重力异常相关关系, 并应用重力数据 (结合地震测深资料)探讨了该区的深 部地壳构造及地壳块体划分. 结果表明: 穿越该区的 4 条琏合带或断裂带将地壳区分为 5 个

号背斜)的褶彼雁列角较小, 中段 (4 号背斜)倠列角较大. 除 1 号背斜外, 其余各背斜的东侧或 东北侧均在逆倾滑或逆走滑的断面上发育了具有擦痕的断裂, 其中西北和东南段为逆倾滑, 擦痕 侧伏角近直立, 中段为逆走滑, 擦痕侧伏角近 $19^{\circ}$, 用其雁列角、雁行间隔以及剪切带宽度的均 值 ${ }^{[4]}$ 计算得到表 1 , 表明该剪切带的西北和东南段曾受到压剪切作用中的压应力比中段大.

表 1 青海柴达木盆地水鸭子墽反“ $S$ ”型剪切带几何学与力学参数关系表

\begin{tabular}{|c|c|c|c|c|c|c|c|c|}
\hline 分段 & 㕍列角 & 间陣/ $/ \mathrm{km}$ & 宽度/ km & 擦痕侧伏角 & $t$ & $\varphi \mathrm{K}$ & K & u \\
\hline $\begin{array}{c}\text { 西北段 } \\
3 \text { 号背斜 }\end{array}$ & $5^{\circ}$ & 12.8 & 1.6 & $85^{\circ} 45^{\prime}$ & 4.02 & 1.0692 & 6.5434 & 13.4205 \\
\hline $\begin{array}{c}\text { 中段 } \\
4 \text { 号背斜 }\end{array}$ & $12^{\circ}$ & 9.1 & 1.6 & $18^{\circ} 48^{\prime}$ & 2.8754 & 0.8349 & 5.8306 & 9.9949 \\
\hline $\begin{array}{l}\text { 东南段 } \\
6 \text { 号背斜 }\end{array}$ & $6^{\circ}$ & 12.3 & 1.6 & $87^{\circ} 40^{\prime}$ & 3.8539 & 1.0373 & 6.4628 & 12.9197 \\
\hline
\end{tabular}

因此, 压应力大的两段断面擦痕侧伏角大, 褶铍体积大 (即间隔长), 应变能大 (即 $\mathrm{u}$ 值大), 中段断面擦痕侧伏角小, 視坡体积小, 应变能也小, 结果回答了孙殿卿先生 30 年前提出的水鸭 子墩反“ $S$ ”形构造的各个背斜断裂的性质为何互相不同 ${ }^{[4]}$ 的问题. 这实例说明了在地质构造 研究中开展广义边界力研究的重要性.

致谢本工作为国家地震局地震联合基金资助项目。

\section{参考文 献}

1 黄庆华. 雁行褶铍构造式的解析理论及实验探讨. 中国科学. B 辑, 1974, (5): 492 501

2 铁摩辛柯盖莱. 并性稳定理论. 张楅范译. 北京: 科学出版社, 1965, 403 408

3 谢新生, 阮小平. 雁行构造力学解析与控震意义. 地震学报, 1994, 16(1): 41 48

4 孙段卿, 邓乃恭, 吴佳影, 等. 柴达木盆地㕍行排列和反“S”形构造所表现的运动程式. 见: 李四光等著. 旋卷和一般扭 动构造及地质构造体系复合问题, 第二辑. 北京: 科学出版社, 1958. 13 36 
不同特征的地壳块体, 并与高原东部的各相应地质构造单元作了对比分析, 提出喜马拉雅块体 的不均衡一直从东延续到西部. 冈底斯块体与㒸塘块体虽东西有区别, 但仍可以各自作为一 个连续的块体进行深部结构与构造的研究, 为研究青藏高原整体的构造动力学机制提供了基 础资料.

\section{1 重力探测剖面的布设及其高程与重力场特征}

重力探测剖面基本上沿 $85^{\circ} \mathrm{E}$ 经线, 从喜马拉雅山北麓的吉隆起始, 经萨嗄、过措勤、改则 到鲁谷, 全长 $582 \mathrm{~km}$. 此重力剖面跨越喜马拉雅块体北部、冈底斯块体、芫塘块体等构造单元 和雅鲁藏布江琏合带、班公湖-怒江断裂带等多条大小不等的构造单元(图 1). 此重力剖面共 有 150 个有效重力测点的高程值和重力异常值. 其分布曲线表示于图 2.

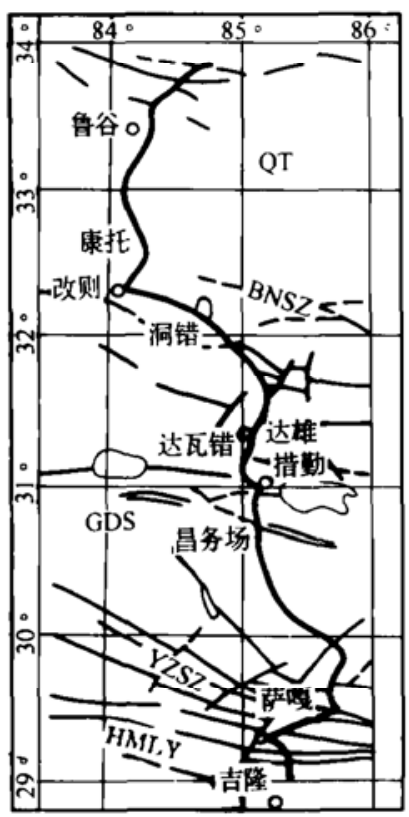

图 1 重力测线分布图

黑粗实曲线为测线. HMLY一一喜马拉雅 块体, GDS一一冈底斯块体, QT 一一美塘块 体, YZSZ一雅㙰藏布琏合带, BNSZ班公湖.怒江断裂带

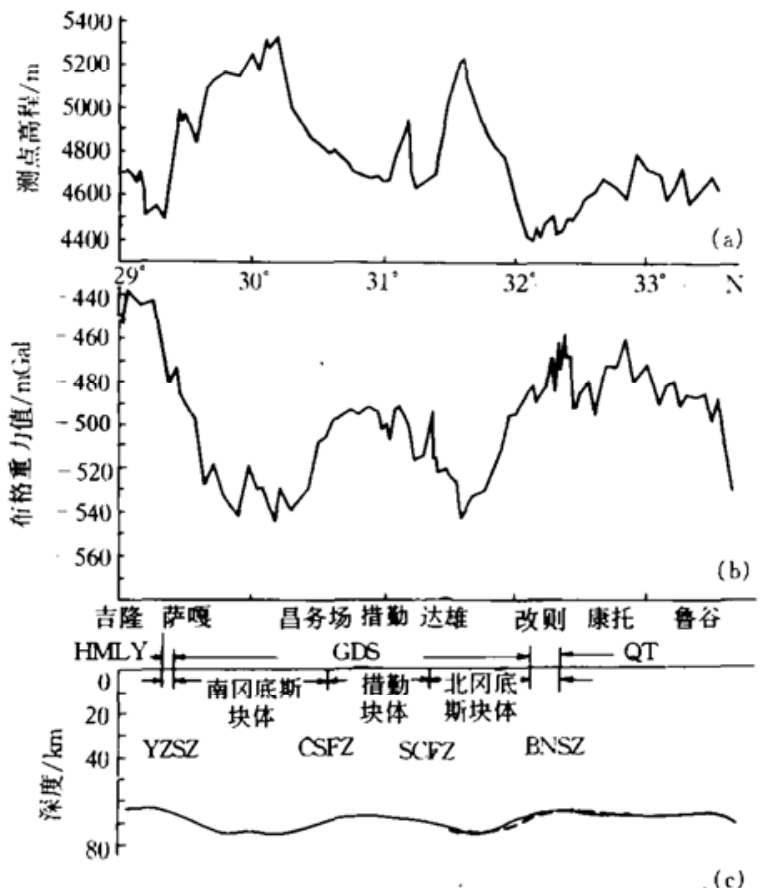

图 2 吉隆·鲁谷剖面的测点高程(a)、布格重力 异常 (b) 和地壳厚度分布 (c)

线段为地震测深的莫霍面.CSFZ一南措勤断裂带, SCFZ一啲泉河 措锄断裂带、YZSZ, BNSZ, HMLY, QT 和 GDS 表示同图 1

由图 2(a) 可见, 测线在喜马拉雅北簏和雅鲁藏布江一带的高程为 $4500 \sim 4700 \mathrm{~m}$. 在冈 底斯山系, 一般在 $5000 \mathrm{~m}$ 以上. 在措勤一带则相对较低, 为 $4600 \sim 4800 \mathrm{~m}$ 之间. 措勤以北 山地, 地形较高, 为 $4900 \sim 5200 \mathrm{~m}$. 到洞错湖、改则一带, 系 $4500 \mathrm{~m}$ 左右的较低的谷地. 进 入康托以北的差塘地区, 平均高程为 $4700 \mathrm{~m}$ 左右.

由图 2(b)表明, 吉隆一带为很高的重力异常值, 达到 $-440 \mathrm{mGal}$; 到萨嗄附近减至 -480 $\mathrm{mGal}$; 冈底斯山南侧地区, 重力异常值再骤减至 $-520 \mathrm{mGal}$. 在此地段形成一个重力异常高 梯度带, 梯度值达 $2.6 \sim 2.8 \mathrm{mGal} / \mathrm{km}$. 进入冈底斯山地, 重力值变低, 在 $-540 \sim-520 \mathrm{mGal}$ 
间变动. 在昌务场一带, 重力值又迅速上升到 $-490 \mathrm{mGal}$ 左右. 此带段重力梯度为 1.5 $\mathrm{mGal} / \mathrm{km}$ 左右. 措勤附近地区, 重力值较高, 但变化较平缓, 在 $-500 \sim-490 \mathrm{mGal}$ 之间. 在 达雄以北的山地, 重力值减低至 $-530 \mathrm{mGal}$, 此段带的重力梯度为 $0.8 \sim 0.9 \mathrm{mGal} / \mathrm{km}$. 洞错、 改则谷地重力值上升至 $-460 \mathrm{mGal}$, 此段的重力梯度也达到 $0.9 \mathrm{mGal} / \mathrm{km}$ 左右. 与南段的重 力梯度带呈对应的形态. 进入美塘地区后, 重力值较高, 其变化幅度小, 一般在 $-470 \sim-490$ $\mathrm{mGal}$ 之间. 这样, 剖面的布格重力异常分布格局是 “高 低 高 低 高” 的形式, 在高值与 低值区之间是重力梯度带.

根据重力学理论, 在基本均衡的状态下, 布格异常和地形高程具有负相关关系, 引起负相 关的机理是地球内部均衡补偿效应. 因此, 由于构成各地质构造单元的地壳物质的密度与厚 度等物性与形态不同, 其相应均衡补偿的质量盈亏也不同, 致使布格重力值随地形变化的相关 程度也不相同, 其相关关系曲线就呈现差异. 应用这种地壳构造的区域补偿差异的特性, 对吉 隆-鲁谷剖面的布格重力异常与测点高程进行相关分析, 以探讨此地区地壳构造单元的区分. 根据剖面跨越的各块体的测点高程 ( $h)$ 和布格重力异常 $(\Delta g)$ 和 $(h-\Delta g)$ 相关回归直线 (图 3), 可以显示出各地质构造单元的 $(h-\Delta g)$ 相关直线的位置和斜率等形态有所差异. 依此相关分 析的结果, 可以区分出不同的块体单元. (1)喜马拉雅块体: 图 3 直线 1 表示该块体的 $(h-\Delta g)$ 关系为正相关关系. 这种 $(h-\Delta g)$ 正相关的原因主要是由于该地体深部处于质量过剩的不均 衡状态所致. (2) 冈底斯块体: 根据测点高程与布格重力异常的分布特征, 冈底斯块体分为 3 个次级块体: (a) 南冈底斯块体: 为冈底斯块体在 $30^{\circ} 40^{\prime}$ 纬线以南部分的山地. 以回归直线 2 表示, 呈现 $(h-\Delta g)$ 是负相关关系. 表明南冈底斯块体基本上处于接近地壳均衡的状态; (b) 措 勤块体: 地表为昌务场至达瓦错的断裂分布较多的低山地和盆地地区. 其 $(h-\Delta g)$ 回归直线 3 , 为正相关关系. 反映该块体处于地壳厚度较薄、深部质量有所过剩的地壳不太均衡的状态; (c) 北冈底斯块体: 在达雄以北到洞错、改则以南的山地部分, 其对应的回归直线 4 与南冈底斯 的回归直线 2, 基本上平行, $(h-\Delta g)$ 相关关系也是负相关. 块体的地壳也是处于基本均衡的 状况. (3) 芫塘块体: 在康托以北到鲁谷一带, 为高原和小起伏山地. 其 $(h-\Delta g)$ 相关直线 5 表 现为负相关关系, 反映该块体处于地壳均衡的状态下.

\section{2 深部地壳构造}

根据布格重力异常数据, 采用地壳平均密度, 剩余密度差为 $-0.43 \mathrm{~g} / \mathrm{cm}^{3}$, 并以本地区仅 有的洞错到鲁谷段由地震测深得到的莫霍界面的资料作为对照数据, 经过重力正反演计算, 给 出吉隆-鲁谷剖面的地壳底界面起伏变化的深部地壳构造特征 (见图 2(c)). 重力计算的莫霍 界面结果与地震测深结果 (图 2(c)的虚线段)在两个块体地壳厚度的差异上相当接近.

由图 2(c) 可见, 地壳底界面有明显的起伏变化. 经分析可以划分出不同的地壳构造单元 元: (1) 喜马拉雅 (北部) 地壳厚度相对缓变区: 此区重力值很高, $(h-\Delta g)$ 正相关, 表明高密度地 幔物质上升较高, 地壳相对较薄, 其厚度在 $62 \sim 63 \mathrm{~km}$ 左右; (2) 雅鲁藏布地壳厚度陡变带: 该 带处于喜马拉雅和冈底斯两块体之间的琏合带地段, 两块体地壳厚度相关很大, 此琏合带处在 地壳厚度陡变的过渡地带. 在此处地壳厚度由 $63 \mathrm{~km}$ 陡变至 72 73 km 左右; (3) 南冈底斯 地壳厚度缓变区: 此区地表为山地, 其地壳相应较厚, 为 $72 \sim 74 \mathrm{~km}$; (4) 南措勤地壳厚度陡变 带: 此带位于 $30^{\circ} 40^{\prime} \mathrm{N}$ 左右至昌务场附近, 此带在重、磁、大地电磁场中分别表现为重力、地磁 高梯度带和电阻率变化带 ${ }^{1}$. 地壳厚度由 $72 \sim 73 \mathrm{~km}$ 转变至 $69 \sim 70 \mathrm{~km}$; (5) 措勤地壳厚度缓 
变区:此区地壳厚度相对较薄, 变化 幅度也较缓, 为 $66 \sim 68 \mathrm{~km}$; (6) 措勤 北地壳厚度陡变带: 该带与址泉河申扎断裂构造带对应, 是地壳厚度较 薄的措勤块体向地壳较厚的北冈底 斯块体转变的带段; (7) 北冈底斯地 壳厚度缓变区: 此区对应的是达雄到 改则的山地, 地壳厚度达 $73 \sim 74$ $\mathrm{km}$; (8) 洞错-改则地壳厚度陡变带: 此带为班公湖-怒江琏合带经过的地 带. 地震测深显示莫霍界面深度有 近 $10 \mathrm{~km}$ 的突变 ${ }^{1)}$. 根据重力计算. 在此带地壳厚度由 $73 \sim 74 \mathrm{~km}$ 变为 65 66 km; (9) 南羌塘地壳厚度缓变 区:此区地表系高原平地和丘陵, 为 $(h-\Delta g)$ 负相关的、地壳基本均衡的 地区, 地壳厚度在 $66 \sim 68 \mathrm{~km}$ 之间变 化.

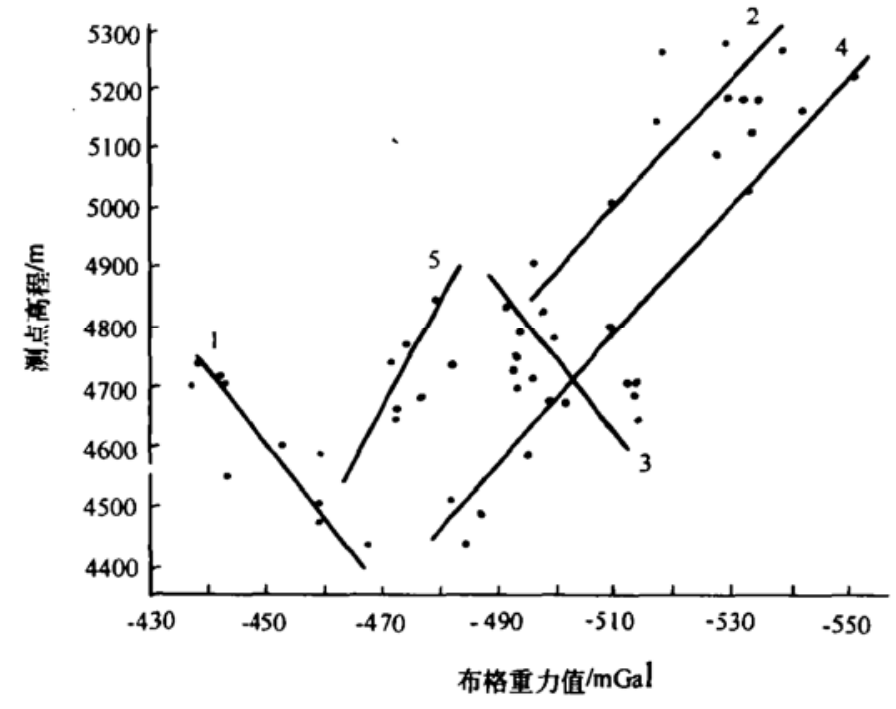

图 3 吉隆-目谷布格重力异常与测点 高程相关统计图

1一一亳马拉雅块体, 2 一一南冈底斯块体, 3一一措勤

块体, 4 一一北冈底斯块体, 5一美塔块体

这样, 根据重力与其他地球物理资料等深部资料分析表明, 吉隆-鲁谷地区存在着 4 个地 壳厚度陡变的琏合带与断裂带, 和由其区分的 5 个地壳厚度相对平缓变化的地壳块体单元.

\section{3 几点认识}

(1)青藏高原过去没有的吉隆至鲁谷北地区的重力实测数据是研究西藏高原西部地壳、岩 石圈的结构与构造以及进一步探讨青藏高原形成与隆升等动力学机制的基本数据和资料.

(2)吉隆-鲁谷北地区的重力场特征、 $(h-\Delta g)$ 相关关系和相应的地壳厚度变化数据综合分 析表明: 该地区存在由 4 个与重力异常高梯度带相对应的地壳厚度陡变带区分出的 5 个地壳 厚度不同的地壳块体的地壳构造格局. 而且和同一断面上的地震测深、大地电磁测深和地磁 探测的研究结果 ${ }^{1}$ 相对比, 彼此都是相互符合的. 这一结果, 除措勤块体外, 其他构造单元皆 以深部地球物理研究证实了前人以地面地质研究对西藏西部各构造地体单元划分的研究成 果.

(3)喜马拉雅块体的 $(h-\Delta g)$ 相关关系在青藏高原西部的本研究区和在高原东部亚东-格 尔木断面 ${ }^{[1]}$ 是相同的. 再有, 东西两断面在喜马拉雅山地都呈现为 $2 \mathrm{mGal} / \mathrm{km}$ 左右的高重力 梯度的相同特征. 这表明喜马拉雅块体的不均衡 ${ }^{[2]}$ 一直从东延续到西部. 同样可进一步认 识到喜马拉雅山系对应的地壳块体的动力学机制在亚东到吉隆这一带段上也是相同的.

(4)吉隆-鲁谷地区的冈底斯南、北块体和差塘块体的各 $(h-\Delta g)$ 相关关系虽然都是负相 关, 但分布形态(斜率)有所不同, 而亚东-格尔木断面的各对应块体也具有同样特征 ${ }^{[1]}$. 表明 冈底斯块体与美塘块体从东到西都可以各自作为一个连续的块体进行深部结构与构造以及动

1) 孔样霞, 王谦身, 熊绍柏. 西藏高原西部综合地球物理与岩石圆结构的研究. 中国科学院地球物理研究所, 1995 
【研究简报】

\title{
大别超高压榴辉岩高温高压下地震波速和 密度的初步实验研究 一对造山带地壳深部组成和莫霍面性质的启示
}

\author{
高 山 $^{(1)}$ 金振民 ${ }^{(1)}$ H. Kern ${ }^{(2)}$ 金淑燕 ${ }^{(1)}$ \\ 许志琴 (3) 董树文 ${ }^{(4)}$ 杨天楠 ${ }^{(3)}$
}

(1)中国地质大学地球科学院, 武汉 430074; (2) Mineralogisch-Petrographisches Institut, Universität Kiel, Germany; (3)中国地质科学院地质研究所, 北京 100037; (4)中国地质科学院南京地质矿产研究所, 南京 210016)

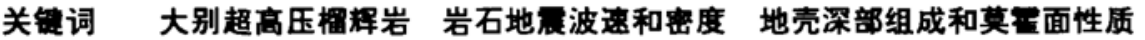

深部岩石高温高压下物理性质是制约地球物理测深成果解释、建立岩石圈物质组成和结 构模式、探讨超高压变质带俯冲和折返机制的先决条件 ${ }^{[1-5]}$, 也是大陆科学钻探先行研究的 重要基础性工作. 地震各向异性(Seismic anisotropy)和 S 波分裂(Shear wave splitting) 研究已 成为揭示岩石圈动力学机制的新方向 ${ }^{[6]}$, 但目前有关超高压岩石的实验数据尚十分缺乏 ${ }^{[5,7]}$. 例如, 目前国际上对榴辉岩地震波速实验研究最详细的成果应属 Fountain 等 1994 年对挪威 加里东造山带榴辉岩的研究 ${ }^{[7]}$, 该研究系统测定了至 $600 \mathrm{MPa}$ 不同压力下榴辉岩和有关麻粒 岩的 $\mathrm{P}$ 波速度和波速各向异性,但未研究 $\mathrm{S}$ 波以及温度对波速的影响. 本文报道了大别超高 压榴辉岩及其围岩在高温高压和组构定向条件下精确测定地震 $\mathrm{P}$ 波、S 波、波速各向异性、S 波分裂、泊松比、密度和体积变化的初步成果, 探讨了实验结果在大别超高压带深部结构、组成 和莫霍面性质研究中的意义.

\section{1 样品采集、制备和实验方法}

对安徽和湖北境内的大别山超高压榴辉岩和各类围岩采集了约 40 件典型新鲜样品, 本文 报道了第一批 7 个样品的实验结果. 实验在德国 Kiel 大学矿物-岩石学研究所进行. 样品制 备成边长为 $43 \mathrm{~nm}$ 的立方体. 为了确保测定精度, 立方体各面均高度抛光, 各组平行面垂直 距离相差 $<0.01 \mathrm{~mm}$. 实验样品的组构定向系统如下: [ $X]$ 为平行线理方向, [ $Y]$ 为垂直线理

力学机制的研究与探讨.

致谢

本工作为国家“攀登”计划资助项目。

\section{参考文献}

1 孟令顺, 高 锐, 周富样, 等. 利用重力异营研究亚东-格尔木地壳构造. 中国地质科学院院报, 第 21 号. 北京: 地质出 版社, 1992. $151 \sim 161$

2 视桓宾, 周文虎, 武立高. 青耗高原重力场特征及其在大地构造上的含义. 地球物理学报, 1985, 28(增刊):60 67 